\title{
The Article Analysis of North China Electric Power University in Recent Years
}

\author{
Yuecong Chen ${ }^{1}$, Baoqing Wang ${ }^{2}$ and Ning $\mathrm{Li}^{3}$ \\ 1.2.3. Library of North China Electric Power University, Beijing 102206, China \\ 1cyc-79@163.com, 2yhewb@163.com,3..In@ncepu.edu.cn
}

Keywords: El; SCl; $\mathrm{CPCl}$; scientific influence.

\begin{abstract}
Based on EI, SCI-E and CPCI-S, the articles of North China Electric Power University (NCEPU) authors were collected and analyzed from 2009 to 2014. It listed the articles, the annual growth rate, first author articles and proportion of first author articles by years. Then it analyzed the articles of SCI-E and CPCI-S database and their scientific influence in the world.
\end{abstract}

\section{Introduction}

EI, SCI and CPCI are the three retrieval tools in the world, and the research articles retrieved by the three retrieval tools are always rewarded in universities and scientific research institutions. North China Electric Power University (NCEPU), as one of the "Project 211" universities, is a national key university under the direct jurisdiction of the Ministry of Education (MOE). The university attaches great importance to research work, is committed to raising the level of scientific and academic, has made great achievements in scientific research. Since the Tenth Five-year Plan, the university has assumed more than 1900 vertical projects from major national research and development projects, Project 973, Project 863, National Science Support Plan, and National Natural Science Foundation of China, and won 162 national and provincial Science Progress Awards. This paper collected the articles of NCEPU in EI, SCI-E and CPCI-S from 2009 to 2014, and analyzed them in detail.

\section{Collect the Articles of NCEPU (2009-2014)}

The articles of NCEPU authors were collected based on Engineering Village and Web of Science from 2009 to 2014. The author address and author affiliation were restricted to "North China Electric University", using the wildcard "**" as " $n *$ china elec* power univ*" or the abbreviated form "NCEPU" or the zip code to search the articles of NCEPU. Then the article database of NCEPU was established according to the above articles after manual selection. There were also miss articles with the address or affiliation "Univ N China Elect Power", "N China Elect Power Ind", "N China Elect Power Inst" which were not usually used in spell, the missing articles were all added to the database.

There were 14183 EI articles, 2998 SCI-E articles and 4074 CPCI-S articles which were as the following Table1.

Table.1 the distribution, growth trend and the proportion of the first author articles

\begin{tabular}{|c|c|c|c|c|c|c|c|}
\hline \multicolumn{2}{|c|}{} & $\mathbf{2 0 0 9}$ & $\mathbf{2 0 1 0}$ & $\mathbf{2 0 1 1}$ & $\mathbf{2 0 1 2}$ & $\mathbf{2 0 1 3}$ & $\mathbf{2 0 1 4}$ \\
\hline \multirow{4}{*}{ EI } & Articles & 1825 & 2320 & 2256 & 2441 & 2629 & 2712 \\
\cline { 2 - 8 } & Growth & & $27.1 \%$ & $-2.8 \%$ & $8.2 \%$ & $7.7 \%$ & $3.2 \%$ \\
\cline { 2 - 8 } & First authors & 1610 & 1997 & 1917 & 2093 & 2204 & 2243 \\
\cline { 2 - 8 } & $\begin{array}{c}\text { Proportion of } \\
\text { first authors }\end{array}$ & $88.2 \%$ & $86.1 \%$ & $85.0 \%$ & $85.7 \%$ & $83.8 \%$ & $82.7 \%$ \\
\hline \multirow{3}{*}{ SCI-E } & Articles & 225 & 316 & 422 & 543 & 612 & 880 \\
\cline { 2 - 9 } & Growth & & $40.4 \%$ & $33.5 \%$ & $28.7 \%$ & $12.7 \%$ & $43.8 \%$ \\
\cline { 2 - 8 } & First authors & 139 & 197 & 289 & 404 & 468 & 670 \\
\hline
\end{tabular}




\begin{tabular}{|c|c|c|c|c|c|c|c|}
\hline & $\begin{array}{c}\text { Proportion of } \\
\text { first authors }\end{array}$ & $61.8 \%$ & $62.3 \%$ & $68.5 \%$ & $74.4 \%$ & $76.5 \%$ & $76.1 \%$ \\
\hline \multirow{3}{*}{ CPCI-S } & Articles & 1072 & 366 & 494 & 840 & 729 & 573 \\
\cline { 2 - 8 } & Growth & & $-65.9 \%$ & $35.0 \%$ & $70.0 \%$ & $-13.2 \%$ & $-21.4 \%$ \\
\cline { 2 - 8 } & First authors & 1068 & 362 & 491 & 839 & 726 & 567 \\
\cline { 2 - 8 } & $\begin{array}{c}\text { Proportion of } \\
\text { first authors }\end{array}$ & $99.6 \%$ & $98.9 \%$ & $99.4 \%$ & $99.9 \%$ & $99.6 \%$ & $99.0 \%$ \\
\hline
\end{tabular}

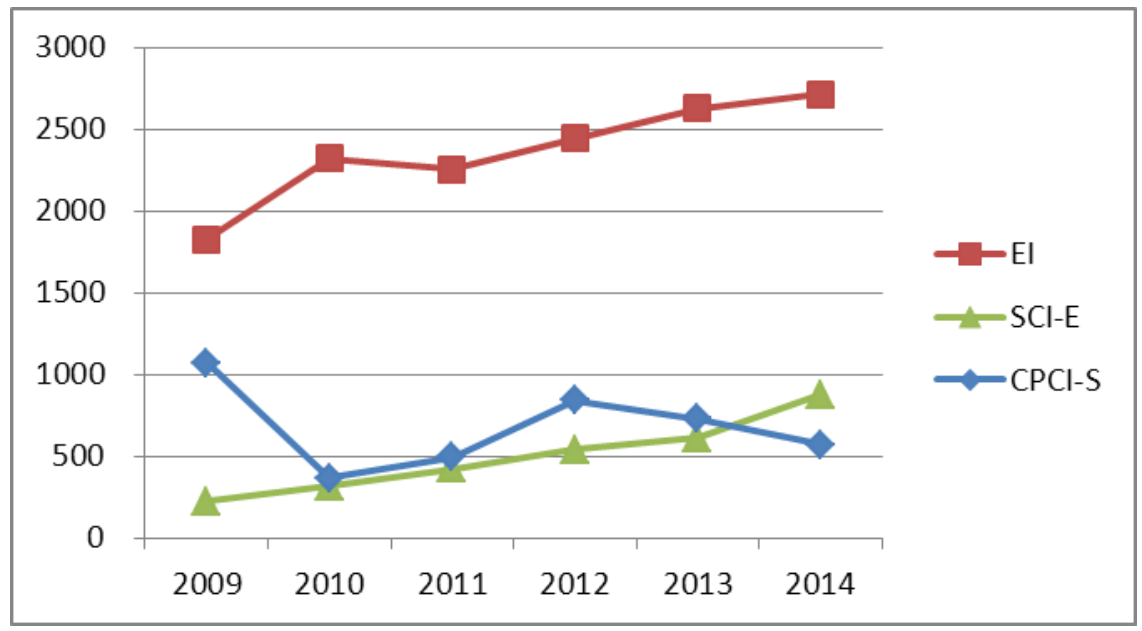

Figure 1. The annual distribution of articles

From Table1 and Fig. 1 the articles of EI and SCI-E showed an increasing trend year by year, the SCI-E articles grew more rapidly than EI, from 225 articles to 880 articles. CPCI-S articles were 1072 in 2009 and decreased to 362 in 2010, this showed that the university attached more attention to the quality of articles than only quantities.

From the proportion of first author, the CPCI-S proportion of first author is highest in the three databases, with a proportion of approximately $99 \%$.

\section{Journal Analysis of All the SCI-E Articles}

There were 758 journals of all the 2998 SCI-E articles, the journals that had number of articles more than 20 were listed in Table 2. The partition of CAS (Chinese Academy of Sciences), journal impact factor, the total citations and articles of NCEPU from 2009 to 2014 were all listed as follows. The journal "RENEWABLE \& SUSTAINABLE ENERGY REVIEWS", "IEEE TRANSACTIONS ON POWER DELIVERY" and "ENERGY" had the most articles of NCEPU, which were 66, 65 and 57.

Table. 2 the journals with more than 20 articles of SCI-E

\begin{tabular}{c|c|c|c|l}
\hline Journal & $\begin{array}{c}\text { Partition } \\
\text { of CAS }\end{array}$ & $\begin{array}{c}\text { Journal IF } \\
\mathbf{( 2 0 1 3 )}\end{array}$ & $\begin{array}{c}\text { Total } \\
\text { citations } \\
(\mathbf{2 0 1 3})\end{array}$ & Articles \\
\hline $\begin{array}{c}\text { RENEWABLE \& SUSTAINABLE ENERGY } \\
\text { REVIEWS }\end{array}$ & 1 & 5.510 & 15,126 & 66 \\
\hline IEEE TRANSACTIONS ON POWER DELIVERY & 3 & 1.657 & 9,325 & 65 \\
\hline ENERGY & 2 & 4.159 & 17,799 & 57 \\
\hline APPLIED ENERGY & 1 & 5.261 & 15,437 & 54 \\
\hline MATHEMATICAL PROBLEMS IN ENGINEERING & 4 & 1.082 & 2,363 & 48 \\
\hline SCIENCE CHINA-TECHNOLOGICAL SCIENCES & 4 & 1.113 & 1,467 & 43 \\
\hline ENERGY POLICY & 1 & 2.696 & 18,983 & 41 \\
\hline
\end{tabular}




\begin{tabular}{c|c|c|c|l}
\hline ACTA PHYSICA SINICA & 4 & 0.845 & 8,589 & 38 \\
\hline $\begin{array}{c}\text { INTERNATIONAL JOURNAL OF ELECTRICAL } \\
\text { POWER \& ENERGY SYSTEMS }\end{array}$ & & & & 36 \\
\hline ENERGIES & 3 & 1.602 & 1,276 & 29 \\
\hline $\begin{array}{c}\text { INTERNATIONAL JOURNAL OF HEAT AND } \\
\text { MASS TRANSFER }\end{array}$ & 2 & 2.522 & 26,902 & 29 \\
\hline $\begin{array}{c}\text { APPLIED THERMAL ENGINEERING } \\
\text { JOURNAL OF HAZARDOUS MATERIALS }\end{array}$ & 2 & 2.624 & 11,248 & 27 \\
\hline CHINESE PHYSICS B & 4 & 4.331 & 55,367 & 27 \\
\hline JOURNAL OF ENVIRONMENTAL INFORMATICS & 2 & 3.773 & 332 & 24 \\
\hline CHINESE SCIENCE BULLETIN & 3 & 1.365 & 9,439 & 23 \\
\hline STOCHASTIC ENVIRONMENTAL RESEARCH & 3 & 2.673 & 1,653 & 23 \\
\hline AND RISK ASSESSMENT & 2 & 3.530 & 16,619 & 22 \\
\hline
\end{tabular}

\section{Subject Distribution of SCI-E and CPCI-S}

The subject distribution of SCI-E and CPCI-S was analyzed statistically on the platform of Web of Science. From the statistics, "ENGINEERING" was more than a half of all the articles and the top 20 subjects were listed in Table 3.

Table.3 The top 20 subject of NCEPU in SCI-E and CPCI-S

\begin{tabular}{|l|c|c|}
\hline \multicolumn{1}{|c|}{ Subject } & Articles & Proportion \\
\hline ENGINEERING & 3752 & $53.531 \%$ \\
\hline ENERGY FUELS & 1504 & $21.458 \%$ \\
\hline MATERIALS SCIENCE & 1399 & $19.960 \%$ \\
\hline COMPUTER SCIENCE & 1249 & $17.820 \%$ \\
\hline AUTOMATION CONTROL SYSTEMS & 674 & $9.616 \%$ \\
\hline PHYSICS & 634 & $9.046 \%$ \\
\hline ENVIRONMENTAL SCIENCES ECOLOGY & 491 & $7.005 \%$ \\
\hline MATHEMATICS & 418 & $5.964 \%$ \\
\hline MECHANICS & 417 & $5.949 \%$ \\
\hline CHEMISTRY & 305 & $4.352 \%$ \\
\hline $\begin{array}{l}\text { OPERATIONS RESEARCH MANAGEMENT } \\
\text { SCIENCE }\end{array}$ & 295 & $4.209 \%$ \\
\hline THERMODYNAMICS & 244 & $3.481 \%$ \\
\hline SCIENCE TECHNOLOGY OTHER TOPICS & 186 & $2.654 \%$ \\
\hline INSTRUMENTS INSTRUMENTATION & 158 & $2.254 \%$ \\
\hline BUSINESS ECONOMICS & 155 & $2.211 \%$ \\
\hline TELECOMMUNICATIONS & 153 & $2.183 \%$ \\
\hline CONSTRUCTION BUILDING TECHNOLOGY & 147 & $2.097 \%$ \\
\hline WATER RESOURCES & 109 & $1.555 \%$ \\
\hline NUCLEAR SCIENCE TECHNOLOGY & 84 & $1.198 \%$ \\
\hline OPTICS & 82 & $1.170 \%$ \\
\hline METALLURGY METALLURGICAL & 66 & $0.942 \%$ \\
\hline ENGINEERING & & \\
\hline
\end{tabular}

\section{Scientific Research Cooperation of SCI-E and CPCI-S}

There were 38 various regions \& countries and 872 articles that cooperated with NCEPU. The countries were mainly concentrated in Canada, USA, Australia and England. 


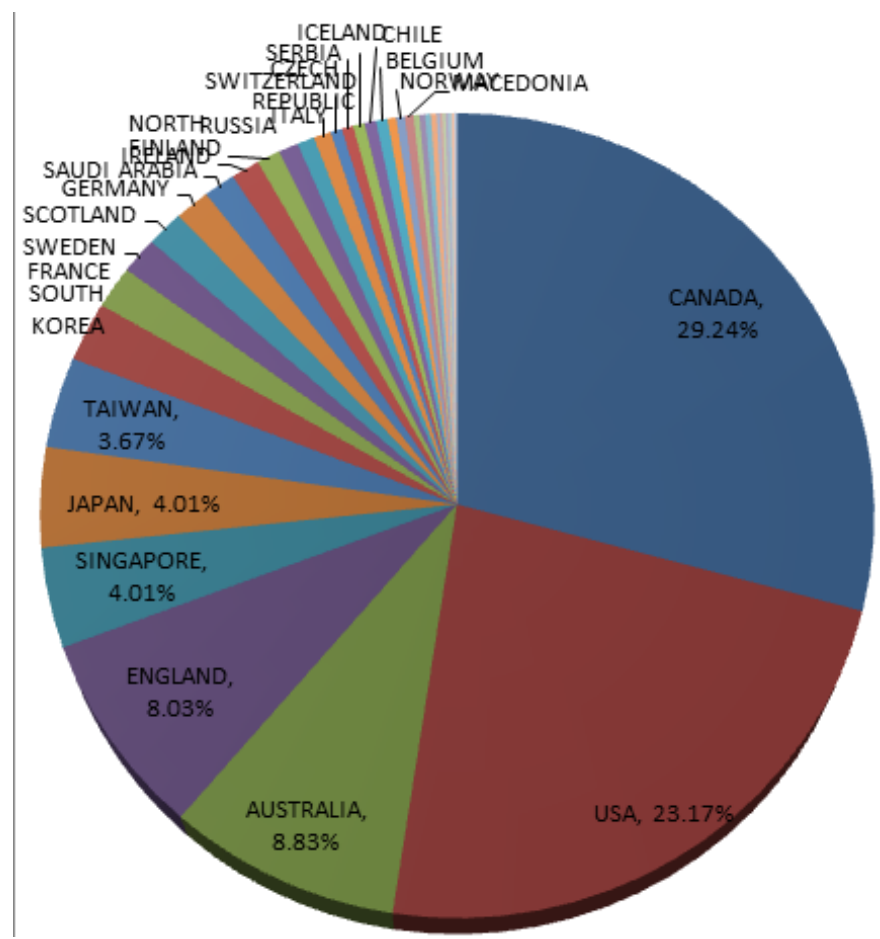

Figure 2. The regions \& countries cooperated with NCEPU and their proportions

There were 803 scientific research institutions that cooperated with NCEPU scattered in 3354 articles. The top 3 were CHINESE ACAD SCI, UNIV REGINA and TSINGHUA UNIV with the proportion of $8.88 \%, 5.13 \%$ and $4.00 \%$.

Table.4 the scientific cooperation institutions of NCEPU in SCI-E and CPCI-S

\begin{tabular}{|l|c|c|}
\hline \multicolumn{1}{|c|}{ Cooperation institution } & Articles cooperated & Proportion in all articles \\
\hline CHINESE ACAD SCI & 298 & $8.88 \%$ \\
\hline UNIV REGINA & 172 & $5.13 \%$ \\
\hline TSINGHUA UNIV & 134 & $4.00 \%$ \\
\hline PEKING UNIV & 70 & $2.09 \%$ \\
\hline BEIJING NORMAL UNIV & 60 & $1.79 \%$ \\
\hline HARBIN INST TECHNOL & 48 & $1.43 \%$ \\
\hline XI AN JIAO TONG UNIV & 41 & $1.22 \%$ \\
\hline SHANDONG UNIV & 39 & $1.16 \%$ \\
\hline HEBEI UNIV & 39 & $1.16 \%$ \\
\hline JILIN UNIV & 31 & $0.92 \%$ \\
\hline UNIV SCI TECHNOL BEIJING & 30 & $0.89 \%$ \\
\hline UNIV SCI TECHNOL CHINA & 29 & $0.86 \%$ \\
\hline BEIJING INST TECHNOL & 27 & $0.81 \%$ \\
\hline ZHEJIANG UNIV & 25 & $0.75 \%$ \\
\hline CHINA ELECT POWER RES INST & 25 & $0.75 \%$ \\
\hline NANYANG TECHNOL UNIV & 23 & $0.69 \%$ \\
\hline BEIJING INFORMAT SCI TECHNOL UNIV & 23 & $0.69 \%$ \\
\hline UNIV ADELAIDE & 21 & $0.63 \%$ \\
\hline BEIHANG UNIV & 21 & $0.63 \%$ \\
\hline TIANJIN UNIV & 20 & $0.60 \%$ \\
\hline
\end{tabular}




\section{Analysis on the Influence of NCEPU Articles in the World}

There were 2289 articles cited in Web of Science platform, with citing articles of 11817. Of all the citing articles there were 6209 articles in Chinese, the other articles scattered in 117 regions \& countries, which reflected the scientific influence of NCEPU in the world.

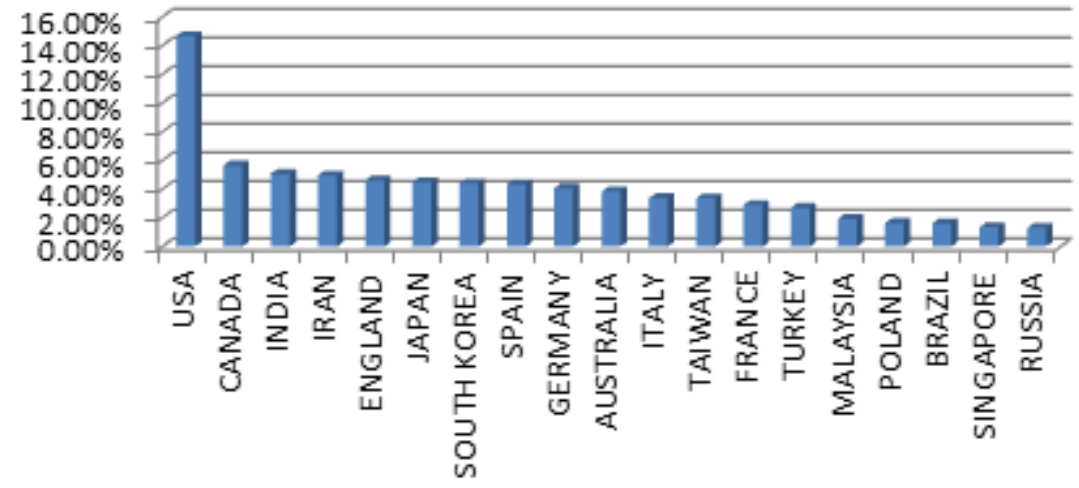

Figure 3. The regions \& countries of citing articles

\section{Conclusion}

The paper collected the articles of NCEPU authors in EI, SCI-E and CPCI-S from 2009 to 2014. The articles of EI and SCI-E were increasing year by year, and the articles of SCI-E increased faster than EI. The university paid more and more attention to the scientific research with the increasing of scientific articles. The authors were paying effort to improve the quality of articles than only quantities. So the articles of CPCI-S decreased a lot and SCI-E articles increased rapidly than before.

Articles of "Engineering" subject were over a half of all SCI-E and CPCI-S articles. And there were 803 institutions scattered in 38 regions and countries that cooperated with NCEPU. There were $76 \%$ articles that cited in Web of Science with 11817 citing articles from 117 regions \& countries.

\section{References}

[1] Web of Science Platform [EB/OL]. http://www.webofknowledge.com.

[2] Engineering Village Platform [EB/OL]. http://www.engineeringvillage.com/ search/quick.url.

[3] Liu Minhui, Hao Yiqin. The Statistical Analysis for Scientific Papers in Yunnan Agricultural University Based on the Data from Science Citation Index Expanded (SCI-E) [J]. Journal of Yunnan Agricultural University, 2015, 03:55-59.

[4] Dong Zheng'e, Chen Huilan. Investigation into Library Service Model of University Discipline Evaluation on the Basis of ESI and Incites Database [J]. Library Journal, 2014, 11:23-28.

[5] Dong Zheng-e, Chen Hui-lan. Analysis on the Discipline Construction in Donghua University in Terms of ESI and SCI-E Indexed Journal Rank in Categories [J]. Journal of Donghua University (Natural Science), 2012, 01:107-112. 